\title{
Desenvolvimento de Um Pó Simbiótico Para Adição em Produtos Alimentícios
}

NatalySimões Bandiera (I), Raúl Jorge Hernan Castro Gomez (I), Caio Casale Aragon (I), Cínthia Hoch Batista de Souza (I), Elsa Helena Walter de Santana (I), Lina Casale Aragon-Alegro (I)

(I) UNOPAR - Universidade Norte do Paraná (Av. Paris, 675, Jd Piza)

\section{Resumo}

Neste trabalho, desenvolveu-se um pó simbiótico para adição em diferentes produtos alimentícios, com a utilização de microrganismo probiótico e xilo-oligossacarídeo. Para isto, foram realizadas as seguintes etapas: 1) definição das fontes de carbono e de nitrogênio a serem utilizadas, que resultaram em maior população das espécies probióticas (Lactobacillus casei e L. acidophilus) avaliadas, utilizando-se delineamento experimental fatorial fracionado padrão de 2 elevado a 6-4; 2) otimização da concentração de cada componente selecionado na etapa anterior, dos parâmetros e da temperatura para a multiplicação dos probióticos, através de matriz experimental Box-Behnken (3 elevado a 3) além do tempo de incubação; 3) definição do método de secagem do meio formulado contendo probiótico; 4) formulação do pó simbiótico. As populações microbianas foram avaliadas através de análise de variância (ANOVA) e teste de Tukey, ao nível de 5\% de significância, e todas as análises dos dados foram realizadas utilizando-se o programa Statistica. As fontes de carbono e de nitrogênio que, juntas, promoveram maior multiplicação de L. casei e de L. acidophilus foram, respectivamente, $16 \%$ de soro de queijo $(\mathrm{m} / \mathrm{v})$ e $2,5 \%$ de sulfato de amônio $(\mathrm{m} / \mathrm{v})$ e $12 \%$ de soro de queijo $(\mathrm{m} / \mathrm{v})$ e $7 \%$ de extrato de levedura $(\mathrm{m} / \mathrm{v})$. As melhores temperaturas para a multiplicação nos meios definidos foram $35^{\circ} \mathrm{C}$ para L. casei e $39^{\circ} \mathrm{C}$, para L. acidophilus. Não houve diferença nas populações dos dois microrganismos quando enumerados nos meios definidos, após $24 \mathrm{~h}$ e $48 \mathrm{~h}$, indicando que o 
tempo de incubação dos probióticos nos meios, antes da secagem, pode ser de $24 \mathrm{~h}$. $\mathrm{O}$ meio definido e inoculado com $\mathrm{L}$. casei e incubado a $35^{\circ} \mathrm{C}$ foi o que obteve maior população do microrganismo probiótico após secagem, acima de 9 ciclos logarítmicos. O pó desenvolvido foi formulado adicionando-se 3,5 g de xilotriose em $10 \mathrm{~g}$ do pó probiótico contendo $\mathrm{L}$. casei.

Palavras-Chave: Lactobacillus, soro de queijo, xilo-oligossacarídeos, probiótico, prebiótico

Agência de Fomento: Capes 